\title{
A PROTEÇÃO DA INFÂNCIA E A PUNIÇÃO DOS RESPONSÁVEIS EM TEMPOS DE FAKE NEWS: UMA ANÁLISE JURISPRUDENCIAL DO DESCUMPRIMENTO DA VACINAÇÃO OBRIGATÓRIA
}

\author{
CHILDREN'S PROTECTION AND THE PUNISHMENT OF THE RESPONSIBLE IN FAKE \\ NEWS TIMES: A JURISPRUDENTIAL ANALYSIS OF COMPLIANCE WITH THE \\ MANDATORY VACCINATION
}

Felipe da Veiga Dias Doutor em Direito (UNISC) Professor do Programa de Pós-Graduação em Direito (IMED) Passo Fundo / RS / Brasil felipevdias@gmail.com

\author{
Driane Fiorentin de Morais \\ Graduanda em Direito (IMED) \\ Bolsista FAPERGS \\ Passo Fundo / RS / Brasil \\ driane_morais@hotmail.com
}

\begin{abstract}
Resumo: O presente estudo tem como tema a análise das decisões judiciais disponíveis em meio eletrônico acerca da vacinação obrigatória, delimitando-se no debate sobre os discursos coercitivos exercidos pelo Estado a fim de determinar de que modo o Judiciário vem fundamentando estas decisões. Utilizando de uma metodologia de abordagem indutiva, o trabalho foi desenvolvido com o objetivo de analisar os discursos de coerção estatal, juntamente aos aspectos relacionados aos limites envolvidos na liberdade familiar em tomar decisões que confrontam interesses coletivos em contrapeso com o exercício das garantias e direitos humanos de crianças e adolescentes. Por fim, conclui-se pela existência da influência punitiva nas decisões do Poder Judiciário, fato que se comprova por meio das menções à suspensão do poder familiar e na imputação de fato criminoso à conduta dos genitores. Ademais, são adotadas falas jurisdicionais baseadas na igualdade como base para sanções punitivas aos responsáveis, enquanto se ignoram fatores socioeconômicos, os danos sociais aos infantes ou mesmo o atual nível de influência de fatores como as fake news na composição desinformativa brasileira.
\end{abstract}

Palavras-chave: punição; fake news e informação; vacinação obrigatória.

\begin{abstract}
The present study has as its theme the analysis of the judicial decisions available in electronic media about mandatory vaccination, delimiting itself in the debate on the coercive discourses exercised by the State in order to determine how the Judiciary has been supporting these decisions. Using a methodology of inductive approach, the work it was developed with the aim of analyzing the discourses of state coercion, together with aspects related to the limits involved in family freedom in making decisions that confront collective interests in balance with the exercise of guarantees and human rights of children and adolescents. Finally, it is concluded that there is a punitive influence in the decisions of the Judiciary, a fact that is confirmed by the mention of the suspension of family power and in the imputation of a criminal fact to the conduct of the parents. Furthermore, jurisdictional statements based on equality are adopted as the basis for punitive sanctions against those responsible, while ignoring socioeconomic factors, social damage to infants or even the current level of influence of factors such as fake news in the Brazilian disinformation composition.
\end{abstract}

Keywords: punishment; fake news and information; mandatory vaccination.

Para citar este artigo (ABNT NBR 6023:2018)

DIAS, Felipe da Veiga; MORAIS, Driane Fiorentin de. A proteção da infância e a punição dos responsáveis em tempos de fake news: uma análise jurisprudencial do descumprimento da vacinação obrigatória. Revista Thesis Juris - RTJ, São Paulo, v. 10, n. 1, p. 45-66, jan./jun. 2021. http://doi.org/10.5585/rtj.v10i1.17210. 
DIAS, Felipe da Veiga; MORAIS, Driane Fiorentin de. A proteção da infância e a punição dos responsáveis em tempos de fake news: uma análise jurisprudencial do descumprimento da vacinação obrigatória

\section{Introdução}

O presente estudo tem como tema a análise das decisões judiciais disponíveis em meio eletrônico acerca da vacinação obrigatória. Delimita-se assim a apreciação baseada na jurisprudência, sendo essa especificação focada nos debates acerca dos discursos de coerção estatal, juntamente aos aspectos relacionados aos limites envolvidos na liberdade familiar em tomar decisões que confrontam interesses coletivos, em contrapartida com o exercício das garantias e direitos humanos de crianças e adolescentes.

Define-se o problema do presente trabalho em: quais são os discursos/argumentos apresentados nas decisões dos Tribunais de Justiça dos estados frente à questão da vacinação obrigatória em crianças e adolescentes e até onde o Estado legitima o discurso coercitivo/punitivo para assegurar o processo? Nesse contexto, parte-se da ideia da existência de violações, as quais motivaram as manifestações judiciais e que podem ser melhor evidenciadas conforme a especificação de seus fundamentos.

Colaciona-se ainda outro fator contextual à abordagem e que acaba evidenciado nas decisões, a utilização de fake news na argumentação dos genitores. Esse aspecto perpassa os problemas enfrentados em uma sociedade comunicativa e que, por vezes, tem na adoção de instrumentos tecnológicos a composição de processos de desinformação e vulnerabilização de direitos, produzindo danos sociais a parcelas significativas da população.

A fim de promover esta pesquisa, com foco em determinar de que modo o Judiciário vem fundamentando essas decisões que obrigam os genitores e responsáveis a vacinar os filhos menores de idade, adota-se para o estudo a metodologia de abordagem indutiva, visto que se irá partir de bases específicas para um ponto geral, ou seja, significa dizer que primeiramente se delimita a situação pontual dos casos concretos para então adentrar na discussão acerca dessas violações, dos limites coercitivos e nas consequências mais amplas, diretas e indiretas, que afetam crianças e adolescentes.

Combinado com o método inicial, encontra-se o método de procedimento monográfico, o qual utiliza como parâmetro o estudo acerca de um tema específico e de forma crítica, deixando de lado abordagens puramente dogmáticas ou analíticas que pouco questionariam sobre o estudo. Por fim, colaciona-se a técnica de pesquisa da documentação indireta, tendo em vista que se utiliza como fontes obras bibliográficas, livros, periódicos, cobertura midiática do caso, pesquisa jurisprudencial e dados secundários a respeito do tema em questão. 
DIAS, Felipe da Veiga; MORAIS, Driane Fiorentin de. A proteção da infância e a punição dos responsáveis em tempos de fake news: uma análise jurisprudencial do descumprimento da vacinação obrigatória

\section{Análise jurisprudencial e os parâmetros decisórios}

No último boletim epidemiológico apresentado pela Secretaria de Vigilância em Saúde e pelo Ministério da Saúde, publicado em fevereiro de 2020, acerca dos casos registrados de sarampo no Brasil em 2019, constatou-se que houve notificação de aproximadamente 64.765 casos da doença em 526 municípios, sendo confirmados 18.203 (28\%) casos e estando sob investigação 10.893 (17\%) (MINISTÉRIO DA SAÚDE, 2020). A vacinação de crianças e adolescentes no Brasil teve sua primeira resolução jurídica publicada em 1837, sendo reiterada em 1904 (FUNASA, 2017). No entanto, no ano de 2019, registrou-se 15 mortes por sarampo e aproximadamente 18.203 casos da doença no país (GLOBO, 2019). Consoante a isso, a Organização Mundial da saúde (OMS), em parceria com o Centro de Controle e Prevenção de Doenças (CDC), estimou que 140 mil pessoas morreram no mundo em 2018 por causa desta mesma doença (GLOBO, 2019). Em contrapartida, as políticas públicas ${ }^{1}$ desenvolvidas pelo Estado em resposta aos surtos de doenças anteriormente consideradas erradicadas não têm sido suficientes para interromper as consequências causadas por estas patologias em conjunto com a manipulação de informações disponíveis nos meios de comunicação.

Dito isso, inicia-se a pesquisa buscando por meio dos sites dos Tribunais de Justiça dos Estados $^{2}$ decisões acerca do tema em foco, especialmente sobre as respostas jurisdicionais a não vacinação, sendo encontradas: 01 apelação civil do Tribunal de Justiça do Rio Grande do Sul (TJRS), 01 apelação civil e 01 agravo de instrumento julgados pelo Tribunal de Justiça de Santa Catarina (TJSC), 01 apelação civil do Tribunal de Justiça de São Paulo (TJSP) e 02 apelações civis do Tribunal de Justiça do Estado de Minas Gerais (TJMG). Para obtenção inicial, utilizou-se da palavra-chave "vacinação obrigatória" para encontrar as decisões mencionadas nesta pesquisa, demarcando o período inicial em 2013 até o ano de 2019, optandose por fazer a divisão e organização das análises a partir da data de julgamento, para que se possa apreciar conjuntamente a mudança e desenvolvimento dos argumentos apresentados pelas partes. Por conseguinte, segmentam-se primeiramente os argumentos trazidos pelos genitores e, logo após, os fundamentos das decisões proferidas pelos desembargadores dos respectivos tribunais.

\footnotetext{
${ }^{1}$ Acerca do debate sobre as políticas públicas indica-se o texto de Zambam e Kujawa (2017)

${ }^{2}$ Justifica-se que em duas decisões, uma de Santa Catarina e outra de São Paulo, durante a análise os processos entraram em segredo de justiça (não mais aparecendo na consulta jurisprudencial), de modo que as informações ficaram acessíveis para referência na pesquisa apenas em sites alterativos. Em síntese, as informações foram coletadas e analisadas nos Tribunais, porém não havia como indicar para o acesso posterior o mesmo local, motivo pelo qual optou-se nessas duas situações em informar outros endereços que ainda contêm a íntegra dos julgados.
} 
DIAS, Felipe da Veiga; MORAIS, Driane Fiorentin de. A proteção da infância e a punição dos responsáveis em tempos de fake news: uma análise jurisprudencial do descumprimento da vacinação obrigatória

\subsection{Argumentos apresentados pelos genitores}

A primeira manifestação a ser analisada origina-se de uma apelação civil julgada pelo Tribunal de Justiça do Estado do Rio Grande do Sul em 18 de abril de 2013, onde recorria-se de uma sentença desfavorável a uma situação ocorrida em 01 de agosto de 2012, na qual o Ministério Público entrou com uma medida protetiva devido ao fato dos responsáveis pela criança se negarem a vaciná-la, mesmo após técnicos de saúde insistirem. A argumentação dos genitores trazida na apelação era a de que a criança se encontrava em ótimo estado de saúde, inexistindo situações de risco, e que o casal temia pelos efeitos colaterais que as vacinais poderiam vir a causar, da mesma forma que alegaram que certas vacinas não haviam sido devidamente testadas. Por fim, sustentaram que não foram omissos em não proceder a vacinação do menino, mas que estavam apenas preocupados com os malefícios de tal ato (BRASIL, 2013).

O segundo julgado analisado trata-se de outra apelação civil, julgada pelo Tribunal de Justiça do Estado de Santa Catarina em 29 de fevereiro de 2016, contra sentença que determinou aplicação de medidas de proteção ao filho do casal, consistente na realização de todas as vacinas negligenciadas pelos mesmos até aquele momento e na condenação dos réus ao pagamento de multa por infração administrativa prevista no artigo 249 da Lei n.8.069/90. A fundamentação dos apelantes baseava-se na alegação de uma ofensa a seus direitos de liberdade de religião, da mesma forma que invocavam direitos previstos na Constituição e em convenções internacionais, juntando ao recurso estudos contrários à vacinação. Pontuaram fortemente que possuíam crenças religiosas contrárias à vacinação e que a não realização de tal ato não traria nenhum risco à vida da filha do casal, uma vez que se tratava de medida preventiva e a criança encontrava-se saudável (BRASIL, 2016).

No transcorrer dos anos que dividem as duas primeiras decisões percebe-se o endurecimento por parte do Ministério Público, ao menos no sentido de requerer o arbitramento de multa acerca do descumprimento da vacinação, algo não observado no julgado inicial. Ademais, enquanto na primeira situação se percebe o desconhecimento e receio aos efeitos negativos da vacina, no segundo ocorre a sustentação da liberdade religiosa como instrumento de permissão da decisão dos genitores, aludindo a ausência de prejuízos à saúde individual da criança em ambos os casos, mas ignorando o risco coletivo que tal prática oferece.

O terceiro julgado trata-se de apelação civil julgada pelo Tribunal de Justiça do Estado de Minas Gerais em 27 de junho de 2019, onde a genitora recorria da sentença que a condenava em uma multa de 3 salários mínimos devido ao descumprimento doloso das determinações do 
DIAS, Felipe da Veiga; MORAIS, Driane Fiorentin de. A proteção da infância e a punição dos responsáveis em tempos de fake news: uma análise jurisprudencial do descumprimento da vacinação obrigatória

Conselho Tutelar. O argumento utilizado pela parte apelante é de que a família vive em situação de miserabilidade, morando numa favela, na qual a genitora, mãe solteira, não consegue sair para procurar emprego pois tem um pai enfermo e acamado e um filho menor de idade para cuidar, motivo pelo qual não conseguia sair para levar a criança nas consultas necessárias anteriores à vacinação. Alega também que as ameaças citadas em sede inicial já perderam sua pretensão punitiva pois a conselheira concordou com o perdão pleiteado pela mãe do menino (BRASIL, 2019a)

Nessa terceira situação parecem haver peculiaridades que demonstram os perigos no uso excessivo de ações coercitivas por parte do Estado, visto que o nivelamento uniforme das multas a partir dos anos recentes pode gerar o incremento de desigualdades sociais instaladas (DIAS; ZAMBAM; SILVEIRA, 2019), conforme aparentemente ocorre neste caso.

A quarta manifestação jurisprudencial sob análise é um agravo de instrumento julgado pelo Tribunal de Justiça do Estado de Santa Catarina em 08 de julho de 2019, no qual os genitores recorreram contra uma decisão interlocutória que deferiu tutela provisória para obrigá-los a vacinarem seus filhos. Sustentaram no recurso que os filhos se encontravam em perfeito estado de saúde e que não vislumbravam o alegado "abandono pela ausência de aplicação de algumas vacinas", e que a preocupação da genitora era legítima uma vez que um de seus filhos foi hospitalizado em estado grave quando tinha apenas 02 meses de vida em virtude de uma vacina aplicada no país em que residiam à época dos fatos (Chile) (BRASIL, 2019b).

Assim, na situação narrada evidencia-se pela primeira vez a argumentação acerca de um processo de vitimização anterior, ou seja, alega-se o sofrimento passado para justificar o receio em submeter a criança à vacinação. Embora inexistam provas que sustentem a alegação, não se pode partir da falácia discursiva da genitora, tão somente se deve levar em consideração as dificuldades usuais de visibilidade das vítimas quando se parte das práticas jurisdicionais punitivas.

$\mathrm{Na}$ quinta decisão em análise, novamente apelação civil, julgada pelo Tribunal de Justiça do Estado de São Paulo em 11 de julho de 2019, o Ministério Público recorreu de sentença que julgou improcedente os pedidos para que os genitores regularizassem as vacinas do filho, o que configurava a infração prevista no artigo 249 do Estatuto da Criança e do Adolescente. Os pais alegaram suficiência de cuidados para a manutenção da saúde da criança de 03 anos que até aquele momento não detinha nenhuma vacina, sob a desculpa de que havia riscos de ingestão de "metilmercúrio", substância presente no "timerosal", utilizado para conservar as vacinas. Sustentam ainda que se trata de um conservante cancerígeno e que deve 
DIAS, Felipe da Veiga; MORAIS, Driane Fiorentin de. A proteção da infância e a punição dos responsáveis em tempos de fake news: uma análise jurisprudencial do descumprimento da vacinação obrigatória

prevalecer a consciência, convicção filosófica e a intimidade sobre as obrigações decorrentes do poder familiar (BRASIL, 2019c).

Por fim, a sexta e última decisão analisada é uma apelação civil julgada pelo Tribunal de Justiça do Estado de Minas Gerais em 12 de dezembro de 2019, onde os genitores recorriam de uma ação ajuizada pelo Ministério Público após exaustivas tentativas de conversas e advertência aos responsáveis sobre o risco da não vacinação. No mesmo caso, foi instaurado um inquérito policial pela prática do crime previsto no artigo 268 do Código Penal, sendo que em sede de contestação o casal não negou a conduta, apenas sustentou que a razão de tal escolha foi tomada após inúmeras pesquisas baseadas em artigos científicos e que estes agem de boa-fé pois já vacinaram a filha mais nova. Afirmam juntamente que fazem parte de uma igreja que proíbe a contaminação por vacina e que a imposição do Estado configura violação do poder familiar e ao seu direito à liberdade e crença religiosa. Sustentam ainda que o artigo $14, \S^{\circ}$, do Estatuto da Criança e do Adolescente (ECA) contém "obscuridade", logo, deveria se fazer uma interpretação extensiva já que o texto legal diz respeito aos responsáveis que não prestam a devida assistência por mero descaso, o que não se configuraria nesta situação (BRASIL, 2019d).

Das situações verificadas nos julgados essa última foi a única em que o Ministério Público fez a imputação de condutas delitiva aos genitores, sendo distinta das anteriores que ficavam restritas às coerções das multas e outras sanções administrativas da órbita do Direito da Criança e do Adolescente, mas distante da atuação penal.

\subsection{Fundamentos apresentados pelos Tribunais}

No relatório da primeira apelação analisada, julgada pelo Tribunal de Justiça do Estado do Rio Grande do Sul, o relator inicia a apreciação citando o artigo 14 do Estatuto da Criança e do Adolescente (BRASIL, 1990), o qual versa sobre a obrigatoriedade da vacinação em crianças, para então falar sobre o avanço científico no Brasil e no sistema de vacinação obrigatória regido pelo Calendário Básico de Vacinação da Criança (Portaria nº 3.318/2010).

Em sequência, observa-se a interpretação acerca da legislação vigente e a liberdade dos responsáveis frente à vacinação, já que o caso diz respeito à saúde pública, superando, desta forma, o interesse do particular. Conclui que, somente em casos excepcionais, nos quais um profissional da área médica, de forma motivada e justificada atue, pode-se determinar que certa criança possui hipersensibilidade à determinada dose de vacina, o que se leva em conta para indicar o afastamento da aplicação da lei, mas que não se constata no caso em tela. Finaliza ressaltando que a vacinação não tem como objetivo o combate de doenças já adquiridas, mas 
DIAS, Felipe da Veiga; MORAIS, Driane Fiorentin de. A proteção da infância e a punição dos responsáveis em tempos de fake news: uma análise jurisprudencial do descumprimento da vacinação obrigatória

sim a prevenção destas, citando o artigo 98, I, do Estatuto da Criança e do Adolescente, e deferindo a medida protetiva prevista no artigo 101 do mesmo estatuto (BRASIL, 2013).

No segundo julgado, realizado pelo Tribunal de Justiça do Estado de Santa Catarina, o relator pontua primeiramente que o casal já tinha sido alvo de outro caso similar, sendo aquela demanda acolhida e mantida em sede de apelação para obrigá-los a vacinar a filha mais nova. Garante, de forma fundamentada, que não há conflito de direitos e que os responsáveis estariam utilizando de suas crenças religiosas para negar direitos fundamentais à filha. Cita, em seguida, o artigo 227, caput, da Constituição Federal brasileira, a Lei 8.069/90 (ECA) e a Convenção sobre os Direitos da Criança (Decreto n. 99.710/90).

Complementa ainda dizendo que não nega o direito dos pais em proceder com a educação dos filhos de acordo com suas próprias convicções, todavia, destaca que é dever do Estado assegurar à criança e ao adolescente os direitos à vida e à saúde previstos na Constituição. Além disso, refuta a ideia de que a vacinação traria malefícios para a criança citando um dialeto conhecido no direito que diz que "alegar e não provar é quase o mesmo que não alegar". Finaliza o relatório destacando que já é a segunda ação movida em face dos genitores e que não é obrigação do julgador analisar exaustivamente todos os dispositivos legais invocados pelos apelantes quando resolve de forma satisfatória a lide, de acordo com a previsão do artigo 93, X, da Constituição Federal (BRASIL, 2016).

No caso seguinte, processado e julgado pelo Tribunal de Justiça do Estado de Minas Gerais, destaca-se inicialmente no relatório que os crimes de ameaça mencionados pelas partes não dizem respeito à matéria do recurso e que o "perdão" concedido não é razão plausível para reforma da sentença. De forma posterior, cita a Lei $\mathrm{n}^{\circ}$ 8.069/90 (ECA), em seu artigo $14, \S^{\circ} \mathrm{e}$ o artigo 249 da mesma fundamentação legal, concordando que os elementos trazidos em autos configuravam prova suficiente da omissão da genitora, destacando ainda que houve inúmeras tentativas de conversa e advertências ignoradas pela recorrente.

Dito isso, fundamenta-se a decisão com dois julgados, sendo um sobre abandono de incapaz e outro sobre criança com grave desvio de conduta (ato infracional), ressaltando que a imposição de sanção tem por objetivo obrigar a mãe a exercer "corretamente" o poder familiar e que esta deveria utilizar de todos os meios ao seu alcance para evitar que seu filho adoeça. Por fim, negaram provimento ao recurso, sugerindo que eventual pedido de parcelamento deva ser feito ao juízo de execuções (BRASIL, 2019a).

O quarto recurso verificado foi um agravo de instrumento, no Tribunal de Justiça do Estado de Santa Catarina, no qual o relator inicia lembrando as partes que o objeto de análise são os requisitos legais para autorizar a suspensão de determinada obrigação imposta aos 
DIAS, Felipe da Veiga; MORAIS, Driane Fiorentin de. A proteção da infância e a punição dos responsáveis em tempos de fake news: uma análise jurisprudencial do descumprimento da vacinação obrigatória

genitores, além de que a decisão recorrida foi publicada sob vigência do novo Código de Processo Civil. Discute o relator de forma rápida a concessão da gratuidade da justiça, a qual concede citando jurisprudência sobre o tema, ao mesmo tempo que lembra as partes que o deferimento de tal benefício em sede de recurso não assegura no juízo originário a gratuidade, e concluindo que o recurso é cabível, tempestivo e que preenche os demais requisitos de admissibilidade, passando então a analisar os pedidos.

Ressalta o julgado que não se evidenciam todos os requisitos do artigo 995, parágrafo único, do Código de Processo Civil, para que se defira o efeito suspensivo, além de concordar com o Ministério Público em sua intervenção para garantir a vacinação, trazendo no relatório uma notícia midiática sobre a volta de doenças anteriormente consideradas erradicadas. Traz ainda em sua argumentação o Calendário Básico de Vacinação da Criança (Portaria $\mathrm{n}^{\circ}$ 1.498/2013) e o Plano Nacional de Imunização (Lei Ordinária 6.259/1975 e Decreto 78.231/1976), garantindo que a saúde é um direito fundamental com previsão legal no artigo 14, $\S 1^{\circ}$, do Estatuto da Criança e do Adolescente, além de jurisprudência sobre a temática em foco. Foi negado provimento ao recurso e concluído que não havia razões plausíveis para retardar a imunização das crianças e expô-las junto à sociedade a riscos desnecessários (BRASIL, 2019b)

No quinto julgado, decidido pelo Tribunal de Justiça do Estado de São Paulo, o Ministério Público recorreu de sentença que não conheceu do pedido de obrigar os pais a vacinarem os filhos. Preenchidos os requisitos para conhecer da apelação, o relator inicia falando sobre a inexistência de base científica para a alegação de que o conservante das vacinas possui qualquer caráter cancerígeno. Sobre isso, destaca o trabalho da FDA nos EUA e sua recomendação no uso do "timerosal", além de que houve ainda uma redução significativa de vacinas atuais que utilizam este componente, logo, existindo a alternativa de vacinação sem esta substância para todas as vacinas necessárias da criança.

Prossegue ainda ao rejeitar a apreciação de reportagens oriundas da internet juntadas pelo casal e reconhece que não há confirmação científica do que eles alegam, destacando no relatório uma publicação feita por uma pesquisadora da área acerca do declínio da cobertura imunológica na população. Ressalta ainda que alguns países estão utilizando da imposição da vacinação, uma vez que há surtos de doenças antes consideradas erradicadas, aplicando multa às pessoas que não aderirem à vacinação, já que se visa proteger a coletividade (BRASIL, 2019c)

Ademais, fundamenta citando os artigos $4^{\circ}, 7^{\circ}$ e $14^{\circ}$ do Estatuto da Criança e do Adolescente, a fim de afirmar que a saúde da criança tem prioridade absoluta sobre o interesse 
DIAS, Felipe da Veiga; MORAIS, Driane Fiorentin de. A proteção da infância e a punição dos responsáveis em tempos de fake news: uma análise jurisprudencial do descumprimento da vacinação obrigatória

dos particulares, além de mencionar o artigo $3^{\circ}$ da Lei $6.295 / 1975$, que dispõe sobre a organização das ações de Vigilância e Epidemiológica do Programa Nacional de Imunização. Cita também o Decreto 78.231/1976, em seu artigo $29^{\mathrm{a}}$, juntamente ao artigo 10, VIII, da Lei 6.437/1997, e o artigo 268 do Código Penal. Continua a argumentação trazendo uma doutrina sobre o assunto e conclui que a recusa em proceder à vacinação não caracteriza o exercício legítimo de um direito, mas sim um ato ilícito e ofensa aos direitos da criança e do adolescente. Menciona brevemente o artigo $5^{\circ}$ da Constituição (BRASIL, 1988), que diz respeito ao princípio da legalidade e justifica mais uma vez com uma menção à doutrina (BRASIL, 2019c).

Finaliza a decisão concluindo que a recusa dos pais em proceder com a vacinação gera, ao mesmo tempo, descumprimento das normas sanitárias, risco concreto à saúde e bem-estar da criança e risco de contaminação coletiva por conta da diminuição da população imunizada. Reconhece a obrigatoriedade da vacinação e a imposição aos genitores para regularizar a vacinação da criança, sob pena de incidir no artigo 265 do ECA, e de sofrer por força estatal a busca e apreensão da criança, a ser cumprida pelo Conselho Tutelar, além de que tal medida decorre da possibilidade de suspensão do poder familiar em virtude do abuso de poder por parte dos genitores. Foi dado provimento à apelação com um voto divergente, que se limitava à discordância da aplicação da medida de busca e apreensão em caso de inobservância da decisão, preferindo deixar a cargo do juízo de primeiro grau a aplicação gradativa da decisão, para que se proteja o interesse da criança e a ordem jurídica (BRASIL, 2019c).

O sexto e último recurso foi uma apelação julgada pelo Tribunal de Justiça do Estado de Minas Gerias, na qual o relator inicia falando sobre a controvérsia da legitimidade do Estado em interferir na escolha dos pais de vacinação, citando o artigo $6^{\circ}$ e o artigo 196 da Constituição Federal (BRASIL, 1988), seguido de uma citação doutrinária sobre o assunto e dos artigos $4^{\circ} \mathrm{e}$ $7^{\circ}$ do ECA (BRASIL, 1990). Logo, menciona a utilização do Sistema Único de Saúde (SUS) nesse cenário e o Programa de Imunização criado pelo Ministério da Saúde, concluindo que o Poder Público deve desenvolver políticas públicas a fim de garantir a saúde das crianças (o que parece indicar a leitura de que tais políticas servem de instrumentos para efetivação de direitos), uma vez que se nota um preocupante reaparecimento de casos de Sarampo no Brasil em 2019 (BRASIL, 2019d).

Explica ainda que há em causa o princípio do melhor interesse da criança e do adolescente, advindo da primazia da dignidade humana, a qual garante à criança e ao adolescente o direito fundamental de chegar à condição adulta sob as melhores garantias morais e materiais, finalizando com a citação do artigo 227 da Constituição Federal (BRASIL, 1988), e destacando que os genitores não podem se recusar a vacinar os filhos. Além disso, analisa a 
DIAS, Felipe da Veiga; MORAIS, Driane Fiorentin de. A proteção da infância e a punição dos responsáveis em tempos de fake news: uma análise jurisprudencial do descumprimento da vacinação obrigatória

motivação dada pelas partes em face das questões religiosas, refutando tal justificativa uma vez que o interesse do menor de idade se sobrepõe a qualquer interesse particular do genitor e que o direito à liberdade religiosa não é um direito absoluto, citando trechos trazidos pela própria parte apelante sobre a posição da Igreja que frequentam em relação ao tema, e destacando que esta permite aos seus adeptos escolher a forma pela qual propagarão suas crenças, finalizando a discussão com um precedente do STJ acerca de uma transfusão de sangue em testemunha de Jeová (BRASIL, 2019d).

Por fim, destaca que não se vislumbra qualquer violação ao poder familiar, já que não se trata de opção, mas sim de garantia ao direito constitucional da criança, citando que no boletim de ocorrência a genitora alegou que somente o genitor seria contra a vacinação. Desqualifica as pesquisas apresentadas pelo casal, publicadas em revistas de média para baixa avaliação no sistema "Qualis", e traz, por fim, jurisprudência acerca da vacinação obrigatória, concluindo com a negativa de provimento ao recurso (BRASIL, 2019d).

\section{Fragilidades discursivas: fake news como ponto de afetação da fundamentação dos genitores}

As similaridades encontradas nas argumentações apresentadas pelos genitores e responsáveis nos recursos partem da ideia de que, uma vez que a criança se encontra em pleno estado de saúde, não se torna necessária aplicação da medida preventiva, já que inexiste situação de risco. Outrossim, nota-se a ideia de que vacinas não são suficientemente testadas e que oferecem altos riscos à saúde por causarem efeitos colaterais, baseando-se em estudos duvidosos publicados em revistas de baixa qualidade ou até mesmo em casos excepcionais de reação à vacinação.

Além disso, encontra-se em cinco dos recursos analisados a argumentação de que obrigar os genitores a proceder com a vacinação configuraria afronta ao direito de liberdade e de religião dos pais. Sustentou-se ainda o risco de ingestão de "metilmercúrio", substância supostamente presente no conservante usado para vacinas, e que o artigo 14 do ECA (BRASIL, 1990) possuía uma "obscuridade", já que o mesmo foi redigido para situações em que os pais não prestavam a devida assistência ao menor de idade por mero descaso. Houve, no decorrer das análises, apenas uma decisão que não detinha os argumentos mencionados acima, por se tratar de um caso onde a genitora não havia procedido com a vacinação em decorrência da miserabilidade em que vive e pela impossibilidade de sair de casa para realizar tal ato.

Inicialmente cabe esclarecer que alguns dos argumentos dos genitores estavam alicerçados em falsas fundamentações, artigos ou notícias. Posto isso, clarifica-se que com o 
DIAS, Felipe da Veiga; MORAIS, Driane Fiorentin de. A proteção da infância e a punição dos responsáveis em tempos de fake news: uma análise jurisprudencial do descumprimento da vacinação obrigatória

aumento no acesso à internet, especialmente, as redes sociais ganharam um destaque importante e crescente nos debates cotidianos, como as discussões políticas e a expansão de informações na área da saúde. Contudo, esse mecanismo abriu campo para discussões cujo conteúdo era verídico e factual, ao mesmo tempo que também promoveu discursos travestidos de meias verdades, não verdadeiras (mentiras) e não factuais, o qual chamou-se de Fake News (RUEDIGER, 2018, p. 6).

Nesse sentido, alguns dos debates são operados por perfis automáticos, também identificados como bots (robôs) (VAROL, 2017, p. 280), os quais são utilizados nessas redes para produzir e reproduzir notícias inverídicas com a finalidade de deturpar, ocultar, mentir, manipular informações sobre uma pessoa ou assunto. Salutar mencionar que a utilização para fins políticos no Brasil foi verificada por recente estudo da Universidade de Oxford, a qual apontou o uso de milícias digitais no país (BRADSHAW; HOWARD, 2019, p. 1).

A cobertura da vacinação no país voltou a se tornar uma preocupação perante as autoridades competentes quando, em 2017, o país atingiu seu mais baixo nível de alcance dos últimos 16 anos, com índices que variaram entre 70,7\% e 83,9\% (FOLHA, 2018). No ano seguinte, o Ministério da Saúde lançou o programa "Saúde Sem Fake News", visando combater a desinformação na área da saúde e garantir que o programa de vacinação fosse realizado com êxito (MINISTÉRIO DA SAÚDE, 2018).

Essa movimentação demonstra o impacto negativo dos processos ligados às fake news, produzindo desinformação e manipulação orientadas por determinados agentes públicos e privados, o que afeta no caso em específico a compreensão geral da população a respeito do tema da vacinação de crianças (por vezes relacionado a movimentos anticientíficos como aqueles nomeados como "antivacina").

Em uma pesquisa em determinada página na rede social Facebook, a qual contava com aproximadamente 5.530 pessoas, no ano de 2004, Ferro e Caldas (2019, p.18) encontraram inúmeras notícias falsas acerca da vacinação, as quais chegaram a garantir uma suposta existência de risco de autismo em crianças que receberam a dose correta e obrigatória das vacinas. De acordo com as imagens coletas na pesquisa, percebe-se que o grupo afirmava que a chance de uma criança vacinada ter autismo é de $420 \%$ maior do que as de crianças que não recebiam. Em síntese, a utilização de números inexistentes, porém colossais, para além de assustar os genitores que teriam acesso a esta Fake News, trabalham com o medo enquanto ferramenta discursiva (que captura o futuro), manipulando e operando técnicas para obter o resultado desejado (AMARAL, 2017, p. 249). 
DIAS, Felipe da Veiga; MORAIS, Driane Fiorentin de. A proteção da infância e a punição dos responsáveis em tempos de fake news: uma análise jurisprudencial do descumprimento da vacinação obrigatória

Além disso, de acordo com um estudo feito pela ONG Avaaz, conjuntamente à Sociedade Brasileira de Imunizações (SBIm), constatou-se que 67\% dos brasileiros acreditam em pelo menos uma informação incorreta sobre vacina, isto é, quase sete em cada dez brasileiros acreditam em notícias imprecisas ou falsas. Ademais, 57\% dos entrevistados que não se vacinaram ou até mesmo não vacinaram suas crianças, alegaram razões contendo informações inverídicas, como os efeitos colaterais ou a desnecessidade da vacinação. E, por fim, $48 \%$ das pessoas ouvidas relataram utilizar das redes sociais como uma das principais fontes de informação, inclusive sobre a vacinação (AVAAZ, 2019, p. 06).

A imensa visibilidade obtida por esse tipo de conteúdo acaba despertando interesse em empresas empenhadas em divulgar suas marcas nas redes sociais, ao mesmo tempo que não se sabe se estas possuem como único objetivo sua própria divulgação ou se também estão apoiando de forma pública a ideia repassada no conteúdo divulgado. Na pesquisa realizada pela Avaaz, por exemplo, identificou-se duas empresas conhecidas no país: Hyundai, empresa automobilística, e a Vivo, que é uma empresa telefônica (AVAAZ, 2019, p. 50 - 51).

Nesse contexto, não são somente as empresas que utilizam do alcance das notícias inverídicas para lucrar ou se autopromover. Em 2018, o então presidente da Banca Evangélica no Congresso brasileiro, o pastor Takayama (PSC-PR), utilizou de sua rede social "Gospel Prime" para disseminar uma informação que se provou distorcida. Mesmo após explicações do Ministério das Relações Exteriores, o líder religioso não se retratou ou sequer excluiu a postagem do site (ÉPOCA, 2018). Da mesma forma, o atual presidente da Bancada Evangélica, Silas Câmara (Republicanos/AM), em agosto de 2019 publicou em suas redes sociais uma declaração sobre as queimadas e desmatamentos ocorridos na Amazônia, onde alegava que estas não eram tão "imensas" como a mídia nacional e internacional estava divulgando. A informação é oposta aos dados divulgados pelo Instituto Nacional de Pesquisas Espaciais (INPE), que revelou um aumento drástico nas queimadas no mês de agosto de 2019, o que representava 196,5\% a mais do que no mesmo período em 2018 (EXAME, 2019).

Um breve parêntese pode ser feito neste momento, pois a adoção de instrumentais tecnológicos para manipulações e construções fantasiosas da realidade apresenta riscos à democracia, já que se estaria a atingir a confiança nas instituições e a segmentar o debate sobre assuntos de interesse coletivo (KAKUTANI, 2018, p. 84). Ademais, registra-se também que o uso da mentira e manipulação de forma irrestrita costuma ser apontado como uma caraterização de líderes fascistas (STANLEY, 2018, p. 66 - 67), sejam eles políticos ou religiosos. O alerta se dá pela gama de danos sociais já produzidos para crianças e adolescentes no país, em razão 
DIAS, Felipe da Veiga; MORAIS, Driane Fiorentin de. A proteção da infância e a punição dos responsáveis em tempos de fake news: uma análise jurisprudencial do descumprimento da vacinação obrigatória

da afetação na compreensão da vacinação por parte de pais/responsáveis e dos efeitos em cadeia gerados à população.

A divulgação de notícias por parte de representantes políticos é um fato preocupante a ser levado em consideração, uma vez que estes utilizam de seus cargos públicos para ampliar a cobertura dos seus discursos, sendo tal atitude ainda mais crítica quando se trata de representantes religiosos e políticos. Igualmente se pode inferir essa influência pelo fato de que a maior parte das fundamentações apresentadas para não vacinação de crianças ampara-se tanto em fake news, quanto na concepção de que a liberdade religiosa seria uma autorização para o descumprimento de regras coletivas de saúde pública, em razão de se tratar de um direito fundamental (e pelas recomendações de alguns líderes dessas congregações).

Sendo assim, percebe-se a necessidade de que seja transmitida a informação de forma correta e verificada, caso contrário, podem ser causados danos sociais massivos à população (BARAK, 2015), visto que o reaparecimento de doenças antes erradicadas põe em perigo a população como um todo, com ênfase às crianças, consideradas vulneráveis, pois ainda não possuem idade suficiente para realizar a imunização. Logo, "aquele que recebe informação adequada tem possibilidade de formar sua consciência sobre determinado assunto e fazer suas escolhas com conhecimento" (SANCHES; CAVALCANTI, 2020, p. 454), e nesse caso apesar da pluralidade de acesso a informações os genitores acabam não compreendendo a dimensão do impacto da decisão sobre a imunização de crianças e adolescentes.

\section{Fundamentação jurídica e as considerações dos pressupostos da infância}

Nas decisões examinadas constatou-se que o artigo 14 , caput e $\S 1^{\circ}$, do Estatuto da Criança e do Adolescente (BRASIL, 1990) é mencionado 08 vezes, sendo citado 02 vezes na primeira (TJ-RS) e 02 vezes na sexta decisão (TJ-MG), enquanto nas demais é mencionado somente uma vez. Esse dispositivo indica a obrigatoriedade da vacinação conforme as recomendações sanitárias, o que em regra significa a imunização coletiva de todos os infantes conforme os critérios de idade estipulados para cada fase do processo.

Além disso, o artigo $4^{\circ}$ do mesmo dispositivo legal (BRASIL, 1990) é referenciado 03 vezes, e apresenta não somente um instrumento normativo, o qual menciona expressamente a responsabilidade de todos no campo da garantia da saúde na infância, mas também enuncia uma das bases de reorganização do campo: a tríplice responsabilidade compartilhada (LAMENZA, 2011, p. 14). Nesse caso a menção das responsabilidades conjuntas suprime o ideal do menorismo ligado à subsidiariedade (SPOSATI, 2009, p. 38), ou seja, a inação de um dos 
DIAS, Felipe da Veiga; MORAIS, Driane Fiorentin de. A proteção da infância e a punição dos responsáveis em tempos de fake news: uma análise jurisprudencial do descumprimento da vacinação obrigatória

agentes imporia a atuação dos demais, como se fosse uma ordem sucessiva. Isso significa que na reflexão sobre a não vacinação, o Estado, por meio da demanda judicial, não necessita aguardar a efetivação de danos/prejuízos para proteger a criança ou adolescente, já que a atuação é conjugada para prevenir, proteger e defender os interesses dos infantes.

Observa-se ainda que o artigo $7^{\circ}$ do ECA (BRASIL, 1990) é apontado por 02 vezes, estando presente na segunda (TJ-SC) e na sexta decisão (TJ-MG), onde os desembargadores apontaram que "a criança e o adolescente têm direito a proteção à vida e à saúde, mediante a efetivação de políticas sociais públicas que permitam o nascimento e o desenvolvimento sadio e harmonioso, em condições dignas de existência" (BRASIL, 1990).

De acordo com a menção anterior, o dispositivo aludido se enquadra na visão de que a área da infância é composta por um sistema de garantia de direitos, e que a sua concretização implica em instrumentos de efetivação desses mesmos direitos (CUSTÓDIO, 2009, p. 38 - 39). Em resumo, significa dizer que as políticas públicas operam enquanto fatores que trazem direitos fundamentais ao campo concreto, de modo que sua articulação (entre políticas para infância e saúde, em combinação) se torna essencial na imunização enquanto mecanismo de prevenção-preservação da vida e saúde na infância.

Embora o artigo 98, I, do ECA (BRASIL, 1990), seja citado somente no primeiro julgado (TJ-RS), acaba sendo indiretamente aproveitado em argumentações posteriores, mesmo que de forma implícita, haja vista que toca na perspectiva das medidas de proteção que podem ser utilizadas em caso de ameaça aos direitos de crianças e adolescentes.

Nesse sentido, o artigo 249 do ECA (BRASIL, 1990) é mencionado 03 vezes, sendo citado duas vezes na terceira decisão (TJ-MG) e somente uma vez no segundo recurso analisado (TJ-SC). Tal texto legal diz respeito às sanções envolvendo os genitores que descumprem, de forma consciente, com as obrigações necessárias ao bem-estar da criança e do adolescente.

Portanto, nota-se um apelo bastante claro à dogmática, já que as imposições previstas no Estatuto da Criança e do Adolescente (ECA) acabam sendo mencionadas repetidas vezes, no entanto, os princípios da prioridade absoluta (COSTA, 2011, p. 862 - 863) e do melhor interesse (MÉNDES, 2007, p. 108), que se tornam essências ao debate, acabam aparecendo em menor quantidade. Salutar indicar a primazia das regras do Estatuto sobre a sua base principiológica, mesmo que isso não signifique nenhuma espécie de demérito é valioso perceber como alicerces da Teoria da Proteção Integral (CUSTÓDIO, 2009, p. 28) acabam em segundo plano.

Em consoante às menções da Constituição Federal, nota-se que o artigo $6^{\circ}$ deste dispositivo legal é mencionado apenas uma vez, presente na sexta decisão analisada (TJ-MG), 
DIAS, Felipe da Veiga; MORAIS, Driane Fiorentin de. A proteção da infância e a punição dos responsáveis em tempos de fake news: uma análise jurisprudencial do descumprimento da vacinação obrigatória

ao invocar os direitos sociais garantidos pelo texto legal (BRASIL, 1988). Ademais, alude-se também o artigo 196 da Constituição Federal, o qual é mencionado durante o exame do mesmo julgado supracitado (TJ-MG). Em sua redação, fica expresso que "a saúde é direito de todos e dever do Estado, garantido mediante políticas sociais e econômicas que visem à redução do risco de doença e de outros agravos e ao acesso universal e igualitário às ações e serviços para sua promoção, proteção e recuperação" (BRASIL, 1988).

Além disso, o artigo 227 da Constituição Federal (BRASIL, 1988) é referenciado duas vezes, estando presente no primeiro (TJ-RS) e no sexto caso (TJ-MG), estabelecendo a Proteção Integral enquanto matriz de orientação da infância (afastando completamente as heranças do menorismo) (DIAS, 2016) e elencando atores responsáveis pelos direitos delimitados para seara da infância, reconhecendo a peculiaridade de seu estágio de desenvolvimento (PEREIRA JÚNIOR, 2011, p. 133), o que lhes garante alguns direitos e proteções específicas, como no caso da imunização contra doenças e outras medidas de garantia da saúde.

Outro fundamento normativo citado é o Decreto $n^{\circ}$. 99.710/90, que acaba sendo mencionado somente no segundo julgado (TJ-SC), o qual diz respeito à Convenção sobre os Direitos da Criança, estabelecida em 21 de novembro de 1990, visando cumprir com o princípio do melhor interesse da criança.

A Lei Ordinária $n^{\circ}$. 6.259/75 é referenciada duas vezes, sendo exposta na quarta (TJSC) e na quinta decisão (TJ-SP). Referida lei diz respeito à criação do Plano Nacional de Imunização - PIN, tendo sido regulamentada posteriormente pelo Decreto $n^{\circ} .78 .231 / 76$, que é indicado três vezes nos recursos estudados, sendo então citado no quarto (TJ-SC), no quinto (TJ-SP) e no sexto julgado (TJ-MG). O Decreto prevê, em seus artigos 27, parágrafo único, e artigo 29, parágrafo único, respectivamente, que:

\footnotetext{
Art. 27. Serão obrigatórias, em todo o território nacional, as vacinações como tal definidas pelo Ministério da Saúde, contra as doenças controláveis por essa técnica de prevenção, consideradas relevantes no quadro nosológico nacional.

Parágrafo único. Para efeito do disposto neste artigo o Ministério Saúde elaborará relações dos tipos de vacina cuja aplicação será obrigatória em todo o território nacional e em determinadas regiões do País, de acordo com comportamento epidemiológico das doenças.
}

Art. 29. É dever de todo cidadão submeter-se e os menores dos quais tenha a guarda ou responsabilidade, à vacinação obrigatória.

Parágrafo único. Só será dispensada da vacinação obrigatória, a pessoa que apresentar Atestado Médico de contra-indicação explícita da aplicação da vacina (BRASIL, 1975).

Já a Lei de número 6.437/77, em seu artigo art. 10, VIII, é mencionada somente na quinta decisão (TJ-SP), acerca das infrações sanitárias (BRASIL, 1977), bem como, ocorre 
DIAS, Felipe da Veiga; MORAIS, Driane Fiorentin de. A proteção da infância e a punição dos responsáveis em tempos de fake news: uma análise jurisprudencial do descumprimento da vacinação obrigatória

somente uma menção ao artigo 268 do Código Penal, apontando que: infringir determinação do Poder Público, destinada a impedir introdução ou propagação de doença contagiosa, com pena de detenção, de um mês a um ano, e multa (BRASIL, 1940).

É necessário ressaltar que a menção do artigo acima denota dois aspectos a serem levantados. O primeiro deles diz respeito à visão deturpada a respeito do poder familiar, no sentido de rememorar a legitimidade de práticas abusivas, tipicamente menoristas (ditas na época como medidas educativas) (VERONESE, 2012, p. 51 -52), cometidas contra os próprios filhos e infantes de forma geral, sob a guarda de um poder ilimitado sobre aqueles que estivessem sob seus comandos, o que claramente se opõe o Poder Judiciário ao projetar o melhor interesse de crianças e adolescentes (alinhando as bases teóricas do Direito da infância) no caso de vacinação, garantindo-lhes a devida imunização mesmo que contraposta à vontade individual dos genitores.

Em contrapartida ao acerto inicial observado nas fundamentações, corrigindo marcas pretéritas do tratamento da infância e impedindo a produção de danos sociais massivos, há um segundo ponto que levanta um espaço de atenção. Esse aspecto diz respeito à inobservância de elementos factuais, como a situação de miserabilidade que ignora o campo das desigualdades sociais e peculiaridades vividas no país (OXFAM, 2020), juntamente ao predomínio de sanções cada vez mais duras contra os pais.

A última nuance aludida traz o risco da incorporação de discursos punitivos como instrumento de correção aos pais, de maneira a permitir que a seara da infância seja invadida pelas dinâmicas de controle social tipicamente características da seara penal. Portanto, por mais que se entenda correta a ação de proteção e garantia de direitos da infância a respeito da vacinação, isso não significa albergar de forma alguma a recepção de práticas punitivas como solução aos conflitos e demandas sociais envolvendo crianças, adolescentes, pais e responsáveis, já que um sistema ilegítimo (ZAFFARONI, 2001, p. 16) não pode trazer avanços na construção de uma sociedade mais justa e equilibrada para todos.

\section{Conclusão}

Este estudo delimita seu escopo por meio da análise das decisões judiciais dos tribunais de justiça disponíveis em meio eletrônico acerca da vacinação obrigatória. A delimitação da pesquisa no debate acerca dos discursos jurisdicionais tem como base perceber as fundamentações apresentadas tanto pelos envolvidos quanto pelo Poder Judiciário no tocante à garantia de direitos para a infância, bem como a leitura a respeito de quais sanções/punições 
DIAS, Felipe da Veiga; MORAIS, Driane Fiorentin de. A proteção da infância e a punição dos responsáveis em tempos de fake news: uma análise jurisprudencial do descumprimento da vacinação obrigatória

devem ser aplicadas na produção de danos sociais quanto à oposição dos processos de imunização coletiva.

O problema do trabalho se estabelece em determinar quais são os discursos/argumentos apresentados nas decisões dos Tribunais de Justiça dos estados frente a questão da vacinação obrigatória em crianças e adolescentes e até onde o Estado legitima o discurso coercitivo/punitivo para assegurar o processo. Para responder a tal indagação, organizou-se a sistemática nas fundamentações apresentadas pelos envolvidos e pelos desembargadores, a fim de estabelecer a construção e embasamento de cada um dos segmentos envolvidos.

Concluiu-se, assim, que existem marcas, em certa medida, de influência punitiva nas decisões do Judiciário nacional, fato que se comprova por meio das menções à suspensão do poder familiar e na imputação de fato criminoso à conduta dos genitores. Portanto, pode-se cogitar que há ao menos a recepção de aspectos ligados ao ideal da punição como mecanismo de correção comportamental ou social dos responsáveis por crianças e adolescentes.

Além disso, verifica-se no terceiro julgado analisado que, apesar de expostos os fatos que justificaram a impossibilidade da genitora em proceder com a vacinação, o relator afastou os motivos apresentados e ainda manteve a condenação em três salários mínimos, mesmo após ter conhecimento da miserabilidade em que a família vivia, optando por aplicar uma medida repressiva em desfavor da mãe que já se encontrava em uma situação vulnerável.

Não se sustenta a ideia de justiça promovida pelo Judiciário quando o recurso utilizado para garantir a proteção da criança/adolescente é uma sanção econômica que ignora a vulnerabilidade da família, partindo de uma equivocada ideia de "igualdade" para aplicação da sanção mesmo quando provado que a família não estava nas mesmas condições das demais. Ademais, observa-se que o menor de idade não fica alheio à penalidade sofrida pela genitora, sendo alvo do dispositivo legal que prevê sua própria proteção, ou seja, o melhor interesse que almejaria a vacinação do infante acaba não atingido, e a sanção jurisdicional impõe uma camada adicional com a punição familiar que ignora a realidade.

Logo, o poder familiar pode ser flexibilizado na situação in concreto, corretamente para proteção da saúde da criança, porém isso não significa que assiste razão na punição com multa de valor muito além do que a genitora dispunha. Não há como perpetuar a ideia de solução de conflitos sociais quando o Estado e o próprio Judiciário mantêm sua preocupação voltada a proceder com medidas punitivas ao invés de buscar entender os danos causados pela desigualdade social no país e pelo afastamento da linguagem de equidade-proteção trazida pela seara do direito da infância. 
DIAS, Felipe da Veiga; MORAIS, Driane Fiorentin de. A proteção da infância e a punição dos responsáveis em tempos de fake news: uma análise jurisprudencial do descumprimento da vacinação obrigatória

Ademais, tais punições comprometem simultaneamente os genitores e as crianças, os quais deveriam ser alvo de proteção do Estado e não vítimas da visão punitiva e da desinformação social que atinge genitores/responsáveis. Outrossim, não se deve minimizar os impactos das fake news diante dos danos resultantes destas, além de perceber que parte da reprodução de informações falsas procede de líderes políticos e/ou religiosos, os quais detêm um alcance de público imensurável.

Também não se faz possível aplicar exclusivamente a culpa/responsabilidade aos genitores e responsáveis pelas crianças ou adolescentes, uma vez que influenciados por notícias maliciosas acabam desenvolvendo concepções equivocadas acerca da vacinação e enfrentando um Estado que está disposto a punir, rigorosamente, mas que falha ao ignorar as condições sociais e educacionais destes. Igualmente, em nenhuma das situações se realiza qualquer menção à necessidade de prover informações adequadas ou orientações que combatam a desinformação.

Torna-se claro que objetivo deste trabalho não é amparar os argumentos anti-vacina dos pais, até mesmo porque apoiar essas decisões seria o mesmo que legitimar a violação dos direitos de crianças e adolescentes (desrespeitando as bases da proteção integral) e as próprias fake news. Dito isso, é importante entender a falha estatal em amparar uma construção social inclusiva que afaste a propagação de informações inverídicas e ações amparadas em equivocadas leituras de direitos fundamentais, como a liberdade religiosa ou mesmo o exercício do poder familiar.

Embora se compreenda, e defenda, a prioridade dos direitos e da proteção da infância, se deve atentar para a refutação do poder punitivo como solução para demandas envolvendo a seara da infância, sob pena das finalidades pedagógicas, que devem ser estendidas até mesmo aos pais, se perderem no cenário coercitivo estatal. Por tais razões, embora o posicionamento firmado seja na maximização dos direitos da infância e na garantia da vacinação, aparta-se aqui de qualquer apelo à punição como forma de resposta aos problemas sociais enfrentados.

\section{Referências}

AMARAL, Augusto Jobim do. Criminologia como desconstrução - talvez. Revista de derecho penal y criminología. Año VII, nº 9, octubre, 2017.

AVAAZ. Nana Queiroz (Coord). As Fake News estão nos deixando doentes? 2019. Disponível em: https://sbim.org.br/acoes/as-fake-news-estao-nos-deixando-doentes. Acesso em: 30 de abril de 2020. 
DIAS, Felipe da Veiga; MORAIS, Driane Fiorentin de. A proteção da infância e a punição dos responsáveis em tempos de fake news: uma análise jurisprudencial do descumprimento da vacinação obrigatória

BARAK, Greg. The crimes of the powerful and the globalization of crime. Revista Brasileira de Direito. v. 11, n. 2, p. 104 - 114, jul-dez. 2015.

BBC. 3 números que revelam o assustador avanço do sarampo no mundo. Disponível em: https://www.bbc.com/portuguese/internacional-50687205. Acesso em: 29 de abril de 2020.

BRADSHAW, Samantha; HOWARD, Philip N. The global disinformation order: 2019 global inventory of organised social media manipulation. Working Paper 2019.3. Retrieved from The Computational Propaganda Project, Oxford University. Disponível em: https://demtech.oii.ox.ac.uk/wp-content/uploads/sites/93/2019/09/CyberTroop-Report19.pdf. Acesso em: 08 de maio de 2020.

BRASIL. Constituição (1988). Disponível em: http://www.planalto.gov.br/ccivil_03/ Constituicao/Constituicao.htm. Acesso em: 22 de abril de 2020.

BRASIL. Decreto-lei no 2.848, de 07 de dezembro de 1940. Código Penal. Brasília, DF, Disponível em: http://www.planalto.gov.br/ccivil_03/decreto-lei/del2848compilado.htm. Acesso em: 08 de abril de 2020.

BRASIL. Lei Ordinária no 6.259, de 30 de outubro de 1975. Programa Nacional de Imunização. Brasília, DF, Disponível em: http://www.planalto.gov.br/ccivil_03/leis/L6259.htm. Acesso em: 04 de abril de 2020.

BRASIL. Decreto $n^{\circ}$ 78.231, de 12 de setembro de 1976. Organização das Ações de Vigilância Epidemiológica,. Brasília, DF, Disponível em: http://www.planalto.gov.br/ccivil_03/decreto/1970-1979/D78231.htm. Acesso em: 05 de abril de 2020.

BRASIL. Lei no 6.437, de 20 de agosto de 1977. Legislação Sanitária Federal. Brasília, DF, Disponível em: http://www.planalto.gov.br/ccivil_03/LEIS/L6437.htm. Acesso em: 07 de abril de 2020.

BRASIL. Decreto $n^{\circ}$ 99.710, de 21 de novembro de 1990. Convenção Sobre Os Direitos da Criança. Brasília, DF, Disponível em: http://www.planalto.gov.br/ccivil_03/decreto/19901994/D99710.htm. Acesso em: 03 de abril de 2020.

BRASIL. Portaria no 3.318/2010, de 29 de outubro de 2010. Calendário Básico de Vacinação da Criança. Brasília, DF, Disponível em:

https://www.diariodasleis.com.br/busca/exibelink.php?numlink=224117. Acesso em: 02 de abril de 2020.

BRASIL. Tribunal de Justiça de Minas Gerais. Apelação Civil nº 1.0518.18.007692-0/001. 2019 (d). Direito à Saúde. Belo Horizonte. Disponível em: https://www5.tjmg.jus.br/jurisprudencia/pesquisaNumeroCNJEspelhoAcordao.do;jsessionid= ACC480F02C20F2CF8CC1ACDB48B4F840.juri_node1?numeroRegistro=1\&totalLinhas=1 \&linhasPorPagina $=10 \&$ numeroUnico $=1.0518 .18 .007692$

0\%2F001\&pesquisaNumeroCNJ=Pesquisar. Acesso em: 12 de abril de 2020.

BRASIL. Tribunal de Justiça de Minas Gerais. Apelação Civil nº1.0317.17.0153991/001. 2019 (a). Infração Administrativa. Belo Horizonte. Disponível em: 
DIAS, Felipe da Veiga; MORAIS, Driane Fiorentin de. A proteção da infância e a punição dos responsáveis em tempos de fake news: uma análise jurisprudencial do descumprimento da vacinação obrigatória

https://www5.tjmg.jus.br/jurisprudencia/pesquisaNumeroCNJEspelhoAcordao.do?\&numeroR egistro $=2 \&$ totalLinhas $=2 \&$ paginaNumero $=2 \&$ linhasPorPagina $=1 \&$ numeroUnico $=1.0317 .17$. 015399-1/001\&pesquisaNumeroCNJ=Pesquisar\&. Acesso em: 06 de abril de 2020.

BRASIL. Tribunal de Justiça de Santa Catarina. Agravo de Instrumento no 402008702.2019.8.24.0000. 2019 (b). Decisão Monocrática Interlocutória. Florianópolis. Disponível em: https://tj-sc.jusbrasil.com.br/jurisprudencia/731716522/agravo-deinstrumento-ai-40200870220198240000-rio-do-sul-4020087-0220198240000/inteiro-teor731716609?ref=serp. Acesso em: 08 de abril de 2020.

BRASIL. Tribunal de Justiça de Santa Catarina. Apelação Civil nº 2015.033190-1. 2016. Representação Para Apuração de Infração às Normas de Proteção À Criança e ao Adolescente. Chapecó. Disponível em: https://www.jusbrasil.com.br/diarios/documentos/328989383/andamento-do-processo-n2015033190-1-apelacao-civel-07-03-2016-do-tjsc. Acesso em: 04 de abril de 2020.

BRASIL. Tribunal de Justiça de São Paulo. Apelação Civil nº 100328483.2017.8.26.0428. 2019 (c). Acordão. São Paulo. Disponível em: https://migalhas.com.br/arquivos/2019/8/art20190813-12.pdf. Acesso em: 10 de abril de 2020.

BRASIL. Tribunal de Justiça do Rio Grande do Sul. Apelação Civil nº 70053524765. 2013. Medida de Proteção. Porto Alegre. Disponível em:

https://www1.tjrs.jus.br/site_php/consulta/consulta_processo.php?nome_comarca=Tribunal\% 20de $\% 20 \mathrm{Justi} \% \mathrm{C3} \% \mathrm{~A} 7 \mathrm{a} \% 20 \mathrm{do} \% 20 \mathrm{RS} \& v e r s a 0=\& v e r s a o \_f o n e t i c a=1 \&$ tipo $=1 \& \mathrm{id} \_c o m a r c a=$ 700\&num_processo_mask=\&num_processo=70053524765\&codEmenta=7706337\&temIntTe or=true. Acesso em: 02 de abril de 2020.

COSTA, Ana Paula Motta. A perspectiva constitucional brasileira da proteção integral de crianças e adolescentes e o posicionamento do supremo tribunal federal. In: SARMENTO, Daniel; SARLET, Ingo Wolfgang (Coord.). Direitos fundamentais no supremo tribunal federal: balanço e crítica. Rio de Janeiro: Lumen Juris, 2011.

CUSTÓDIO, André Viana. Direito da criança e do adolescente. Criciúma: UNESC, 2009.

DIAS, Felipe da Veiga. O direito à informação na infância online. Curitiba: Prismas, 2016.

DIAS, Felipe da Veiga; ZAMBAM, Neuro José; SILVEIRA, Alexandre Marques. A insustentabilidade social violadora de direitos humanos no modelo de controle penal e a privação das capacitações (capabilities). Pensar - Revista de Ciências Jurídicas, v. 24, n. 4, 2019.

EPOCA. O exército de pinóquios: como operam dez dos maiores sites de notícias falsas do país, pagos até com verba de gabinete para disseminar. Disponível em: https://epoca.globo.com/brasil/noticia/2018/04/o-exercito-de-pinoquios.html. Acesso em: 25 de abril de 2020.

EXAME. Desmatamento na Amazônia nos 12 meses até julho foi o maior em 11 anos. 2019. Disponível em: https://exame.abril.com.br/brasil/desmatamento-na-amazonia-atingeem-2019-maior-nivel-em-11-anos-diz-inpe/. Acesso em: 30 de abril de 2020. 
DIAS, Felipe da Veiga; MORAIS, Driane Fiorentin de. A proteção da infância e a punição dos responsáveis em tempos de fake news: uma análise jurisprudencial do descumprimento da vacinação obrigatória

FOLHA. A trajetória da cobertura vacinal no brasil e a influência das fake news. 2018. Disponível em: https://www1.folha.uol.com.br/cotidiano/2018/06/vacinacao-de-criancas-nopais-atinge-indice-mais-baixo-em-16-anos.shtml. Acesso em: 29 de abril de 2020.

FUNASA. Cronologia histórica da saúde pública. Disponível em:

http://www.funasa.gov.br/cronologia-historica-da-saude-publica. Acesso em: 01 de maio de 2021.

GLOBO. Brasil tem quase 13,5 mil casos confirmados de sarampo em 2019. Disponível em: https://g1.globo.com/bemestar/sarampo/noticia/2019/12/19/brasil-tem-134-mil-casosconfirmados-de-sarampo-em-2019-diz-ministerio-da-saude.ghtml. Acesso em: 28 de abril de 2020 .

GLOBO. Sarampo causou 142 mil mortes no mundo em 2018. Disponível em: https://g1.globo.com/bemestar/sarampo/noticia/2019/12/05/sarampo-causou-140-mil-mortesno-mundo-em-2018-diz-oms.ghtml. Acesso em: 03 de abril de 2020.

KAKUTANI, Michiko. A morte da verdade: notas sobre a mentira na Era Trump. Rio de Janeiro: Intrínseca, 2018.

LAMENZA, Francismar. Os direitos fundamentais da criança e do adolescente e a discricionariedade do Estado. Barueri: Manole, 2011.

MÉNDEZ, Emilio García. A comparative study of the impact of the convention on the rights of the child: law reform in selected civil law countries. In: UNICEF. Protecting the world's children: impact of the convention on the rights of the child in diverse legal systems. New York: Cambridge, 2007.

MINISTÉRIO DA SAÚDE. Boletim Epidemiológico. 2020. Elaborado pela Secretária da Vigilância em Saúde. Disponível em:

https://portalarquivos.saude.gov.br/images/pdf/2020/marco/04/Boletim-epidemiologico-SVS09-final.pdf. Acesso em: 03 de abril de 2020.

MINISTÉRIO DA SAÚDE. Ministério da Saúde lança serviço de combate à Fake News. 2018. Disponível em: https://antigo.saude.gov.br/noticias/agencia-saude/44139-ministerio-dasaude-lanca-servico-de-combate-a-fake-news. Acesso em: 29 de abril de 2020.

OXFAM. Tempo de cuidar: o trabalho de cuidado não remunerado e mal pago e a crise global da desigualdade. Janeiro de 2020. Disponível em: http://www.oxfam.org.br. Acesso em: 04 de março de 2020.

PEREIRA JÚNIOR, Antônio Jorge. Direitos da criança e do adolescente em face da TV. São Paulo: Saraiva, 2011.

PORCELLO, Flávio Antônio Camargo; DIAS, Francielly de Brites Costa. Verdade x mentira: a ameaça das fakenews nas eleições de 2018 no Brasil. In: Congresso Brasileiro de Ciências da Comunicação (41.: 2018 set. 02-09: Joiville, SC). Anais. São Paulo: Intercom, 2018. Disponível em: https://www.lume.ufrgs.br/bitstream/handle/10183/184434/001078994.pdf? sequence=1. Acesso em: 30 de abril de 2020. 
DIAS, Felipe da Veiga; MORAIS, Driane Fiorentin de. A proteção da infância e a punição dos responsáveis em tempos de fake news: uma análise jurisprudencial do descumprimento da vacinação obrigatória

RODRIGUES, Walkíria Machado; VERONESE, Josiane Rose Petry. Papel da criança e do adolescente no contexto social: uma reflexão necessária. Sequiência: Estudos Jurídicos e Políticos, v. 18, n. 34, p. 27-44, 1997.

RUEDIGER, Marco Aurélio. Robôs, redes sociais e política no Brasil: estudo sobre interferências ilegítimas no debate público na web, riscos à democracia e processo eleitoral de 2018. Rio de Janeiro: FGV, DAPP, 2017.

SANCHES, Samyra Haydêe Dal Farra Naspolini; CAVALCANTI, Ana Elizabeth Lapa Wanderley. Direito à saúde na Sociedade da Informação: a questão das fake news e seus impactos na vacinação. Revista Juridica, v. 53, n. 4, p. 448-466, 2020.

SPOSATI, Aldaíza. Modelo brasileiro de proteção social não contributiva: concepções fundantes. In: Concepção e gestão da proteção social não contributiva no Brasil. Brasília: Ministério do Desenvolvimento Social e Combate à Fome, Unesco, 2009.

STANLEY, Jason. Como funciona o fascismo. A política do "nós" e "eles". Porto Alegre: L\&PM, 2018.

VAROL, Onur et al. Online human-bot interactions: Detection, estimation, and characterization. In: Eleventh international AAAI conference on web and social media. 2017.

VERONESE, Josiane Rose Petry. Os direitos da criança e do adolescente: construindo o conceito de sujeito-cidadão. In: WOLKMER, Antonio Carlos; LEITE, José Rubens Morato (Org.). Os "novos" direitos no Brasil: natureza e perspectivas - uma visão básica das novas conflituosidades jurídicas. São Paulo: Saraiva, 2012.

ZAMBAM, Neuro José; KUJAWA, Henrique Aniceto. As políticas públicas em Amartya Sen: condição de agente e liberdade social. Revista Brasileira de Direito, v. 13, n. 1, p. 6085, 2017.

ZAFFARONI, Eugenio Raúl. Em busca das penas perdidas: a perda de legitimidade do sistema penal. 5 ed. Rio de Janeiro: Revan, 2001. 